\title{
Stabilization and treatment of Colles' fractures in elderly patients
}

\author{
This article was published in the following Dove Press journal: \\ Clinical Interventions in Aging \\ 17 November 2010 \\ Number of times this article has been viewed
}

\section{William G Blakeney \\ Department of Orthopedic Surgery, Sir Charles Gairdner Hospital and Royal Perth Hospital, Perth,WA, Australia}

\begin{abstract}
Colles' fractures (fractures of the distal radius) are extremely common in the elderly. These fractures tend to result in displacement in elderly people because they have osteoporotic bone. Fracture displacement in the elderly, however, does not necessarily result in functional impairment. This review looks at the current literature on distal radius fractures in the elderly and the treatment options for stabilization of these fractures. These include conservative management with cast immobilization or surgical options: internal fixation, external fixation, percutaneous pinning, and bone substitutes.
\end{abstract}

Keywords: Colles' fracture, distal radius, elderly, osteoporosis, treatment

\section{Introduction}

Colles' fractures (fractures of the distal radius) are extremely common. They occur more frequently in women than in men. They are the most common fractures in women in the United States and Northern Europe up to the age of 75 years, with a lifetime risk of $\sim 15 \%$. $^{1}$ These fractures have a bimodal age distribution, with young adults and the elderly being the most affected. ${ }^{2}$ In the elderly, they result more commonly from low-energy falls than from high-energy trauma. Eighty-five percent of women who suffer distal radius fractures have been shown to have low bone mineral density and $51 \%$ have osteoporosis. ${ }^{3}$ With the growing number of elderly patients in the developed world, the incidence of these fractures will only increase.

Abraham Colles first described the fracture in 1814 stating, 'One consolation only remains, that the limb will at some remote period again enjoy perfect freedom in all its motions, and be completely exempt from pain; the deformity, however, will remain undiminished throughout life'. ${ }^{4}$ This conviction, however, has since been proved wrong with complete symptomatic and functional recovery after these fractures being much less than guaranteed. ${ }^{5}$

There are a number of options for stabilization and treatment of these fractures. These include conservative management with cast immobilization or surgical options: internal fixation, external fixation, percutaneous pinning, and bone substitutes.

The elderly patient, however, presents unique management issues in the treatment of these fractures. Distal radius fractures in osteoporotic bone have greatly diminished stability; there is often bone impaction and fracture fragmentation. ${ }^{6}$ Surgical fixation is more difficult because the fixation device cannot gain as robust and reliable hold as in younger, good quality bone. ${ }^{7}$ As one would expect, fractures in the elderly therefore tend to displace. ${ }^{8}$
Correspondence: William G Blakeney Department of Orthopedic Surgery, Sir Charles Gairdner Hospital, Hospital Ave., Nedlands, WA 6009, Australia

Tel +6I 0404848 I I4

Email blakeney@gmail.com 
Fracture displacement in the elderly, however, does not necessarily result in functional impairment. Particularly in the low-demand elderly patient, radiological parameters of adequate reduction do not translate into functional or clinical outcomes (see section 'Correlation of radiographic outcomes to functional outcomes in elderly patients').

This review looks at the current literature related to distal radius fractures in the elderly and the treatment options for stabilization of these fractures.

\section{Fracture instability in the elderly}

Fracture instability refers to the tendency of a fracture to displace after manipulation to an anatomic position. Distal radius fractures in elderly people tend to displace because they have osteoporotic bone. In a study involving 125 women aged over 50 years, who suffered distal radius fractures from low-energy trauma, measures of fracture displacement were compared with bone mineral density. ${ }^{9}$ From radiographic measurements, a significant association of increasing deformity with lower bone mineral density was found.

A number of studies have looked at predictors of instability in distal radius fractures treated conservatively. In a series of $\sim 4000$ distal radius fractures, one of the most significant predictors of instability was increasing age. ${ }^{10}$ A prospective study of 645 Colles' fractures treated conservatively also found that age was one of the most important predictors of displacement. ${ }^{11}$ Age above 60 years was a predictor of failure in a study of 112 conservatively managed fractures as well. ${ }^{12}$ Similarly, in a prospective study of 50 patients treated with closed reduction and cast immobilization, age was the only statistically significant risk factor in predicting secondary displacement and instability. ${ }^{13}$

A 2003 study looked at 60 fractures of the distal radius in a low-demand elderly population treated with anatomic reduction and cast immobilization. ${ }^{14}$ They found no correlation between fracture classification, initial displacement, and final radiographic outcome. More than three-quarters of all fractures reverted to a position similar to or worse than the initial deformity.

Another study of 108 conservatively managed elderly patients (age $>65$ years) showed better results, with $74 \%$ having good or excellent radiographic outcomes. ${ }^{15}$ Interestingly though, there was no correlation between radiographic outcomes and functional outcomes. This is a finding that has been observed in many other studies of elderly patients.

\section{Correlation of radiographic outcomes to functional outcomes in elderly patients}

There is good evidence that inadequate anatomic reduction of distal radius fractures in a young patient population corresponds to poor functional outcomes. ${ }^{16-21}$ This, however, does not necessarily translate in an elderly population. On the contrary, numerous studies have in fact found that radiographic outcomes (see Figure 1) do not correlate to clinical outcomes. ${ }^{22-29}$

Two hundred sixteen patients with extra-articular distal radius fractures were prospectively followed for over 1 year. ${ }^{22}$ Misalignment of the distal radius was associated with higher reports of pain and disability in patients $<65$ years of age. In patients aged $>65$ years, however, no radiography parameters examined in isolation or when clustered together were found to affect Patient-Rated Wrist Evaluation (PRWE) or the Disabilities of the Arm, Shoulder and Hand (DASH) questionnaire scores significantly.

In another prospective cohort study, acceptable radiographic reduction was not associated with better self-reported functional outcomes (SF-12 and DASH) or increased satisfaction at 6 months in a cohort of 74 elderly patients with conservatively treated distal radius fractures. ${ }^{23}$

This was further supported by a prospective, randomized study of 57 patients above the age of 60 years, which compared cast immobilization with percutaneous pinning. It found no correlation between radiological parameters and functional outcomes in terms of pain, range of movement, grip strength, activities of daily living, and the SF-36 score. ${ }^{24}$ Another prospective randomized trial of 101 patients above the age of 55 years comparing external fixation with conservative management also found no correlation between final anatomical and functional outcome. ${ }^{25}$

A recent prospective study of 53 patients above the age of 55 years found no relationship between anatomic reduction as evidenced by radiographic outcomes and subjective or objective functional outcomes. ${ }^{26}$

Three smaller studies of 30 or less patients found satisfactory functional outcomes in a majority of patients even though they had unacceptable radiographic alignment. ${ }^{27-29}$

Not all studies, however, have failed to find a correlation between functional outcomes and radiographic outcomes. A retrospective study of 30 patients aged between 56 and 86 years showed significantly worse functional deficit in patients with a malunited Colles' fracture (defined as $>10^{\circ}$ dorsal angulation or $>2$-mm radial shift). ${ }^{19}$ Another retrospective study of 46 patients aged over 55 years comparing 
I.
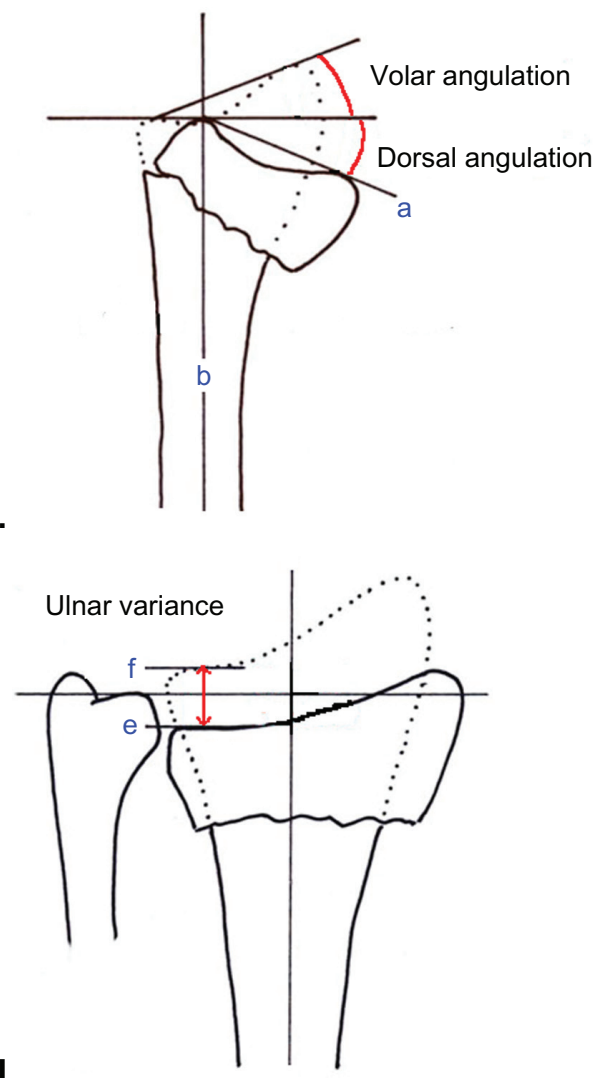

III.

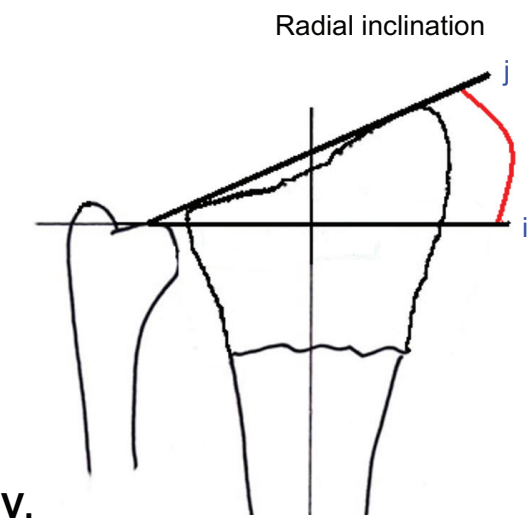

II.

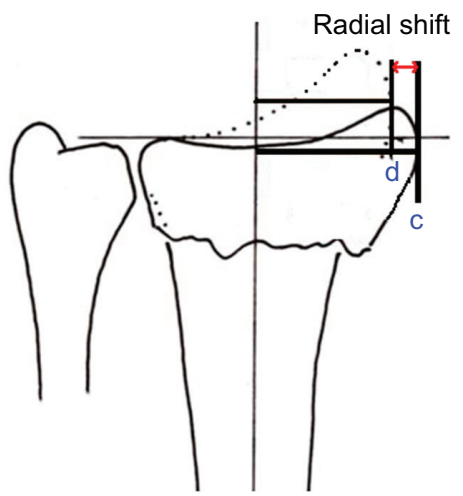

IV.

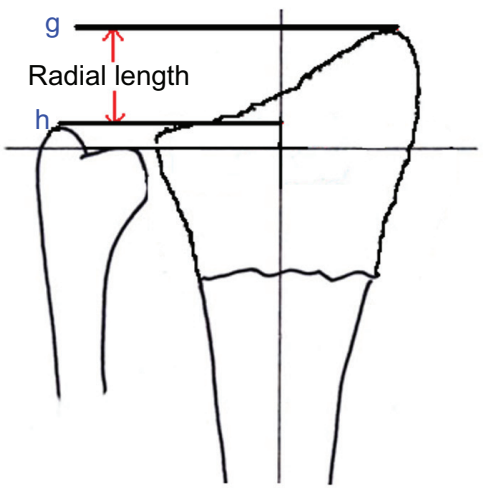

VI.

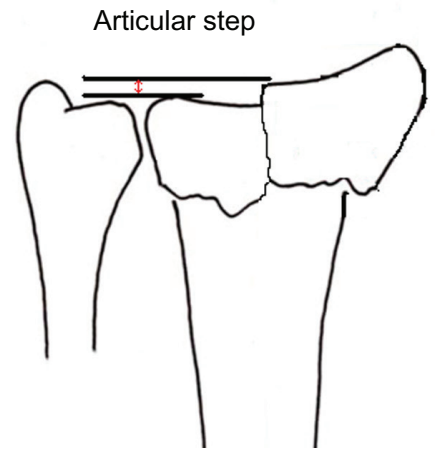

Figure I Radiographic measures of outcome in distal radius fractures. I) Dorsal angulation: The angle between the line which connects the most distal points of the dorsal and volar cortical rims of the radius (a) and the line drawn perpendicular to the longitudinal axis of the radius (b). Normally II $-12^{\circ}$ volar. II) Radial shift: This is a relative measurement, which is taken as the difference between the measurements of the fractured radius (c) and the normal, uninjured radius (d). III) Ulnar variance: Vertical distance between a line drawn parallel to the proximal surface of the lunate facet of the distal radius (e) and a line parallel to the articular surface of the ulnar head (f). Usually negative variance $-I \mathrm{~mm}$. IV) Radial length: Distance between a line drawn at the tip of the radial styloid process, perpendicular to the longitudinal axis of the radius ( $\mathrm{g}$ ) and a second perpendicular line at the level of the distal articular surface of the ulnar head (h). Normally II-I2 mm. V) Radial inclination: Angle between a line perpendicular to the longitudinal axis of the radius (i) and a line joining the distal tip of the radial styloid and the distal sigmoid notch (j). Usually $21^{\circ}-25^{\circ}$. VI) Articular step: Up to $2 \mathrm{~mm}$ is acceptable.

percutaneous wiring with cast immobilization found a strong correlation between functional outcomes (Gartland and Werley demerit point system) and radiographic measures of dorsal angulation and radial length. ${ }^{30} \mathrm{~A}$ third retrospective study of 22 elderly patients only found that functional results were worse when ulnar variance of $>6 \mathrm{~mm}$ was observed..$^{31}$
While treating an elderly patient, the clinician must of course take into account many more factors other than the fracture pattern. One needs to consider medical comorbidities, operative risk, as well as functional demands. A clinician should have a much higher threshold for intervention in an older patient with an unstable or displaced fracture than in a 
younger patient. That is not to say that we should accept poor reduction in all patients over a certain age. The increasing fitness and more active lifestyle of some elderly people these days means they are less likely to accept disability or deformity following a fracture. ${ }^{32} \mathrm{We}$ will consider the treatment options available for the stabilization of these fractures.

\section{Conservative management}

Closed reduction and cast immobilization is the mainstay of treatment for minimally displaced, stable fractures. ${ }^{5}$ Conservative management is also indicated in unstable fractures in low-demand elderly or those considered too frail to undergo surgery. A cohort of 60 unstable distal radius fractures in patients with dementia or multiple medical comorbidities was treated by closed reduction and cast immobilization. ${ }^{14}$ Of these, 53 healed in a malunited position, but functional results were satisfactory. This led the authors to conclude there was little benefit to closed reduction in the very old and frail, dependent or demented patient. These patients can be treated with simple cast immobilization.

A systematic review looked at 37 randomized trials comparing different methods of conservative management. ${ }^{33}$ It concluded there was insufficient evidence to favor any one method of conservative management over another and that the clinicians should therefore use an accepted technique with which they are familiar. In the elderly with unstable osteoporotic fractures, where cast immobilization is not being relied upon to control alignment, the primary role of the cast is for comfort and support. It should therefore be a functional cast, which should be relatively light and not hinder forearm rotation or finger movements.

Early mobilization has been shown to hasten recovery in a randomized prospective trial of 187 patients aged over of 55 years. ${ }^{34}$ Minimally displaced fractures were randomized to treatment either in a conventional plaster cast or in a crepe bandage. Displaced fractures were reduced and the patients were randomized to either be treated conventionally or encouraged to mobilize the wrist in a cast that restricted extension. In both categories, patients encouraged to mobilize the injured wrist from the outset recovered wrist movement and strength more quickly than those immobilized in a conventional plaster cast.

\section{Open reduction internal fixation}

The theoretical advantages of internal fixation of distal radius fractures lie not only in achieving anatomical reduction, but also in establishing stable fixation to allow early range of motion and rehabilitation. Internal fixation devices, however, have a much weaker hold in osteoporotic bone and are therefore more likely to loosen and lose fracture alignment. ${ }^{8}$ Surgical techniques are evolving to allow better control of osteoporotic bone. ${ }^{7}$ Fixed-angle locking screws that lock into the plate do not rely on engagement of the screw thread in bone. They act as a fixed internal buttress transferring the articular loads across the fractured metaphyseal bone to the intact diaphysis (see Figure 2).

With the evolution of the fixed-angle locking plate, there has been a change in the treatment of distal radius fractures in the elderly. ${ }^{35}$ Although these fractures have traditionally been treated nonoperatively, there has been an increasing trend toward operative treatment. This has been highlighted by a study which looked at Medicare data in the United States for distal radius fractures in the elderly. ${ }^{35}$ It showed a fivefold increase, from $3 \%$ in 1996 to $16 \%$ in 2005 , in the rate of internal fixation over the 10 -year time period examined.

This trend toward increased operative intervention is supported by studies examining functional outcomes in the elderly following surgery. A prospective study of 55 patients evaluating the rate of functional improvement after treatment with volar locking plates demonstrated similar rates of recovery between elderly patients (age $>60$ years) and younger patients (age 20-40 years). ${ }^{36}$

A retrospective analysis of 24 distal radius fractures in patients aged over 75 years treated with a volar fixed-angle

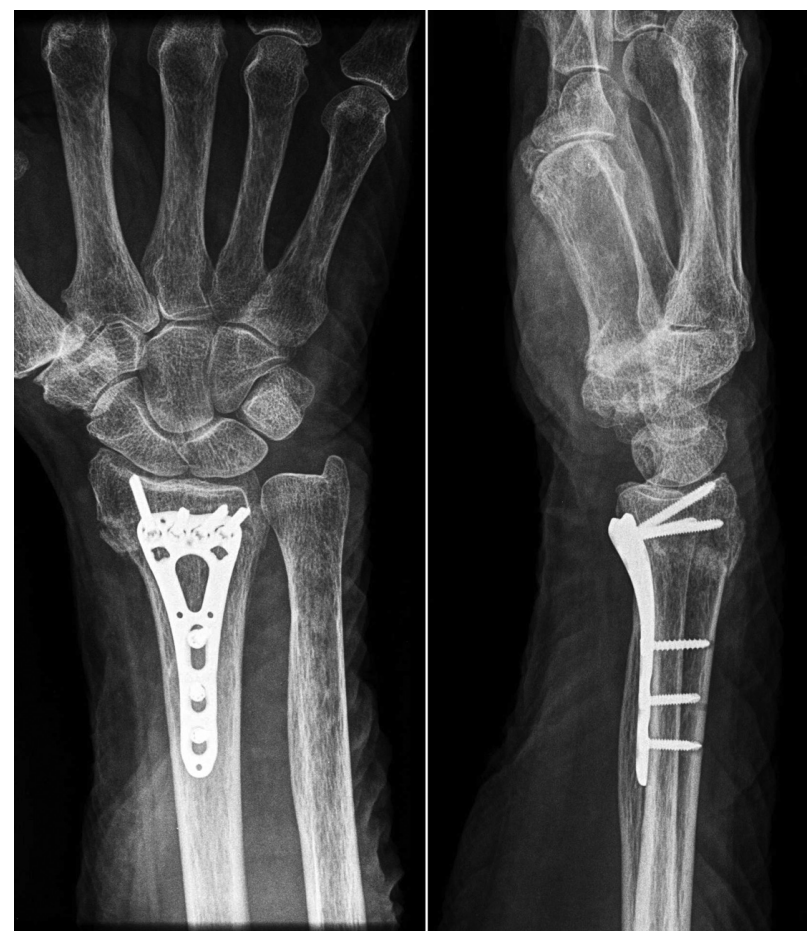

Figure $2 \mathrm{X}$-ray of volar locking plate. 
plate showed good results with no significant loss of reduction. ${ }^{37}$ All patients were able to perform activities of daily living including feeding, hygiene, and general light use of their hands by 2 weeks after surgery. Functional outcomes were comparable to those of younger patients treated with internal fixation.

In another cohort of 20 patients aged over 60 years treated with internal fixation following failed conservative management, 17 had a return to preoperative functional levels. ${ }^{38} \mathrm{At}$ an average follow-up of 38 months, there were 7 excellent, 11 good, and 2 fair results using the PRWE and the physical activity scale for the elderly. There were six plates removed due to dorsal wrist pain - a relatively high number of complications.

Eighteen patients aged over 60 years in another retrospective series were treated with open reduction and internal fixation. ${ }^{39}$ Fifteen patients showed excellent results and three showed good results according to the Gartland and Werley scoring system.

A comparative study of nonoperative treatment with volar locking plating in 70 patients aged over 70 years showed significantly better radiological outcomes in the operative treatment arm..$^{40}$ Despite this, there was no significant difference in functional outcomes.

\section{External fixation}

External fixation of fractures of the distal radius has been in use since the 1940s. ${ }^{41}$ Numerous fixation devices and techniques have been described, and the good results of external fixation have made it a common method for treating complex fractures of the distal radius (see Figure 3). External fixation in elderly patients again presents difficulties due to weak hold of the pins in osteoporotic bone. There are two main techniques of external fixation: wrist bridging (where the distal pins are inserted into the second metacarpal) and nonbridging (where distal pins are inserted into the distal radius fragment). A randomized control trial compared these two different methods of external fixation in a group of 38 elderly patients. ${ }^{42}$ Although there was a slight improvement in radial length (measured on radiographs) at 1 year in the nonbridging group, there were no functional differences between the two.

A randomized controlled trial compared external fixation with conservative management for redisplaced fractures in 43 patients aged over 55 years. ${ }^{25}$ Patients in the external fixation group showed a significantly better anatomical result. However, functional results were not any better than the control group with only $57 \%$ patients having good or excellent results.
A more recent retrospective trial of 46 consecutive patients aged over 65 years compared functional outcomes in patients treated with external fixation with those treated with conservative management. ${ }^{43}$ They found average wrist extension and ulnar deviation were statistically better in the external fixation group at mean follow-up of 25 months. There was no statistically significant difference in the DASH scores in wrist flexion, radial deviation, pronation, supination, grip strength, or pinch strength.

A smaller series looked at 16 women aged over 55 years with intra-articular distal radius fractures treated with external fixation. ${ }^{27}$ Although there was significant secondary displacement in 11 of the patients, the functional outcome was excellent or good in 10 and fair in 2 patients. Only four patients had a poor functional outcome.

One technique to prevent fracture displacement is to use percutaneous pinning as an augmentation to external fixation. Biomechanical studies have shown increased stability. ${ }^{44}$

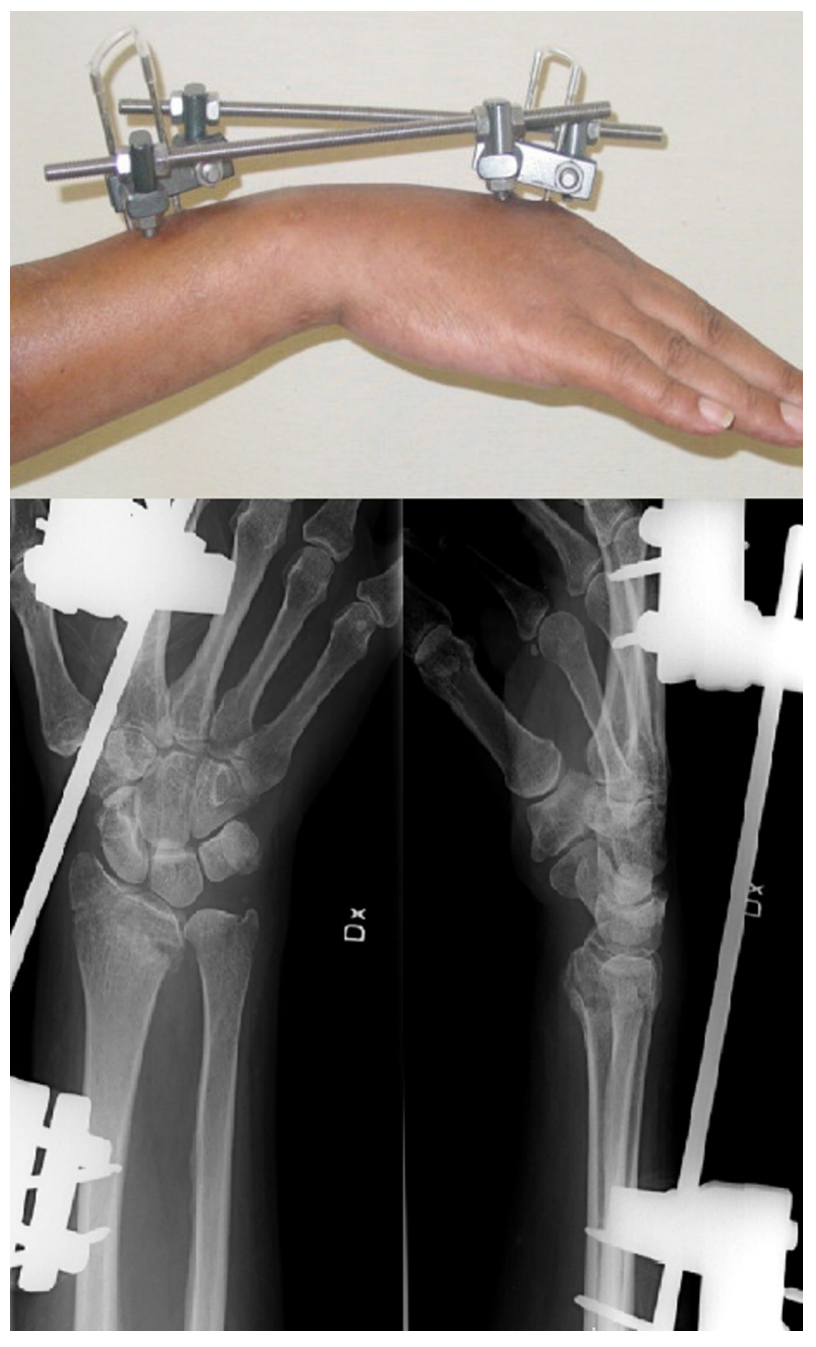

Figure 3 An external fixator. 
A recent study of 32 patients aged over 65 years combined external fixation with percutaneous pinning with good results. ${ }^{45}$ Excellent and good functional results (Gartland and Werley) were seen in $87.5 \%$ of patients. They were compared to a cohort of patients younger than 60 years treated with the same method, and there was no statistical difference in radiographic or functional outcomes.

The main complication of external fixation is pin-tract infection. Complications such as infection, pin loosening, joint stiffness, and nerve injury have been reported to occur in as many as $61 \%$ of patients. ${ }^{46}$

\section{Percutaneous pinning}

The use of percutaneous pins (Kirschner wires) is an accepted practice for treatment of distal radius fractures either alone or as a supplement to external fixation. In severely comminuted or osteoporotic fractures, the trabecular bone of the metaphysis provides little inherent stability. These fractures were considered a contraindication to percutaneous pin fixation. ${ }^{5}$ Most series with older patients have a significant rate of secondary instability after percutaneous pinning. ${ }^{47-49}$

This view is supported by a prospective, randomized trial comparing percutaneous pinning with conservative treatment in 57 patients aged over 60 years with unstable, extra-articular fractures of the distal radius. ${ }^{24}$ It concluded that percutaneous pinning provided only a marginal improvement in the radiological parameters compared with immobilization in a cast alone. This did not correlate with an improved functional outcome.

In contrast, a retrospective study of 46 patients aged over 55 years comparing percutaneous pinning with conservative management had opposing results. ${ }^{30}$ This study used the Kapandji wiring technique where pins are placed directly into the fracture and then into the proximal radius and thus act as mechanical supports. The results showed superior anatomical and functional results in the group treated with Kapandji wiring. Functional results (Gartland and Werley) were excellent or good in 19/23 of the wired group, compared with $12 / 23$ of the plaster group.

\section{Bone substitutes}

In elderly patients with osteoporosis, it is often difficult to fill the void left by impacted metaphyseal bone. Bone substitutes may be injected into this void to support the compromised bone. Initially, polymethylmethacrylate cement was utilized. More recently, the development of bone mineral substitutes promises better integration into the osseous matrix as well as providing similar mechanical properties to the bone.
A Cochrane Review of 10 randomized control trials with bone substitutes found improved anatomical outcomes compared to plaster cast alone in 7 of the trials. ${ }^{50}$ Two trials also found it improved function. Reported complication of bone scaffolding was transient discomfort resulting from extraosseous deposits. These trials were not specific to an elderly population.

A prospective, randomized study compared the outcome of conservative treatment with that using an osteoconductive synthetic material on 110 patients aged over 50 years with fractures of the distal radius. ${ }^{51}$ Patients treated with bone substitute had less pain and earlier restoration of movement and grip strength. Functional results at 1 year were significantly different: satisfactory in $81.54 \%$ of the bone substitute patients and $55.55 \%$ of the control group. The rates of malunion were $18.2 \%$ and $41.8 \%$ in bone substitute patients and the control group, respectively. Complications in the bone substitute group included extraosseous cement deposits causing discomfort in 30 patients and one case of intra-articular cement requiring surgical removal.

Other studies have shown that these bone substitutes may be better used as an adjunct to other forms of fixation rather than in isolation. ${ }^{52,53}$

\section{Fracture prevention}

Distal radius fractures in the elderly are often a result of osteoporosis. ${ }^{9}$ Osteoporosis shows good response to treatment. Physical activity has been shown to reduce fracture risk by increasing bone density ${ }^{54}$ and improving mobility, which decreases the risk of falls. ${ }^{55}$ Calcium supplementation has been shown to increase bone mineral density of the radius. ${ }^{56}$ Combination of vitamin D supplementation with calcium has been shown to reduce risk of fracture in patients aged over 65 years. ${ }^{57}$

In addition to lifestyle changes such as improved diet and increased exercise, there are a number of effective, welltolerated pharmacological therapies that reduce patients' risk of fracture. There is a strong evidence that bisphosphonates reduce the risk of fracture in patients with osteoporosis. ${ }^{58,59}$ Teriparatide, a recombinant form of parathyroid hormone, has been shown to reduce fracture risk in women with osteoporosis. ${ }^{60}$ Raloxifene, a selective estrogen receptor modulator, is effective in preventing postmenopausal bone loss, but reduction of nonvertebral fractures has not been demonstrated. ${ }^{61}$ Intranasal calcitonin has been shown to reduce risk of vertebral fracture, but an effect on nonvertebral fracture risk was not observed. ${ }^{62}$ 


\section{Conclusion}

As can be seen from the studies in this review, there remains no absolute consensus on the best method for treatment of distal radius fractures in the elderly. Many of the trials in this review are observational studies with relatively few enrolled patients. High-powered randomized controlled trials are required to better evaluate the different methods of stabilization in elderly populations.

One thing that the clinician can appreciate from this review is the vast difference in patient characteristics in an elderly population. In an active, healthy patient with an unstable fracture, an attempt at anatomic reduction and fixation through surgical means is more likely to render good functional results. In a low-functioning patient with multiple medical comorbidities, conservative management is a safer option and is likely to give acceptable clinical outcomes, even with malunion. In between these two extremes, treatment decisions need to take into account more than fracture pattern and include premorbid function of the patient, medical comorbidities, surgeon familiarity with techniques, and patient preference.

\section{Disclosure}

The author reports no conflict of interest in this work.

\section{References}

1. Cummings SR, Kelsey JL, Nevitt MC, O’Dowd KJ. Epidemiology of osteoporosis and osteoporotic fractures. Epidemiol Rev. 1985;7:178-208

2. Owen RA, Melton LJ 3rd, Johnson KA, Ilstrup DM, Riggs BL. Incidence of Colles' fracture in a North American community. Am J Public Health 1982;72(6):605-607.

3. Hegeman JH, Oskam J, van der Palen J, Ten Duis HJ, Vierhout PAM. The distal radial fracture in elderly women and the bone mineral density of the lumbar spine and hip. J Hand Surg Br. 2004;29(5):473-476.

4. Colles A. On the fracture of the carpal extremity of the radius. Edinb Med Surg J. 1814;10:182-186.

5. Simic PM, Weiland AJ. Fractures of the distal aspect of the radius: changes in treatment over the past two decades. Instr Course Lect. 2003;52:185-195.

6. Ring D, Jupiter JB. Treatment of osteoporotic distal radius fractures. Osteoporos Int. 2005;16 Suppl 2:S80-S84.

7. Smith DW, Henry MH. Volar fixed-angle plating of the distal radius. $J$ Am Acad Orthop Surg. 2005;13(1):28-36.

8. Walz M, Kolbow B, Auerbach F. DO fixed angle T-plates offer advantages for distal radius fractures in elderly patients? Unfallchirurg. 2004;107(8):664-670.

9. Sakai A, Oshige T, Zenke Y, Suzuki M, Yamanaka Y, Nakamura T. Association of bone mineral density with deformity of the distal radius in low-energy Colles' fractures in Japanese women above 50 years of age. J Hand Surg Am. 2008;33(6):820-826.

10. Mackenney PJ, McQueen MM, Elton R. Prediction of instability on distal radial fractures. J Bone Joint Surg Am. 2006;88(9):1944-1951.

11. Hove LM, Solheim E, Skjeie R, Sorensen FK. Prediction of secondary displacement in Colles' fracture. J Hand Surg Br. 1994;19(6):731-736.
12. Lafontaine M, Hardy D, Delince P. Stability assessment of distal radius fractures. Injury. 1989;20(4):208-210.

13. Nesbitt KS, Failla JM, Les C. Assessment of instability factors in adult distal radius fractures. J Hand Surg Am. 2004;29(6):1128-1138.

14. Beumer A, McQueen MM. Fractures of the distal radius in low-demand elderly patients: closed reduction of no value in 53 of 60 wrists. Acta Orthop Scand. 2003;74(1):98-100.

15. Dayican A, Unal VS, Ozkurt B, Portakal S, Nuhoglu E, Tumoz MA. Conservative treatment in intra-articular fractures of the distal radius: a study on the functional and anatomic outcome in elderly patients. Yonsei Med J. 2003;44:836-840.

16. Gartland JJ Jr, Werley CW. Evaluation of healed Colles' fractures. J Bone Joint Surg Am. 1951;33-A(4):895-907.

17. Bacorn RW, Kurtzke JF. Colles' fracture: a study of two thousand cases from the New York state workmen's compensation board. J Bone Joint Surg Am. 1953;35-A(3):643-658.

18. Gliatis JD, Plessas SJ, Davis TR. Outcome of distal radial fractures in young adults. $J$ Hand Surg Br. 2000;25(6):535-543.

19. McQueen M, Caspers J. Colles fracture: does the anatomical result affect the final function? J Bone Joint Surg Br. 1988;70(4):649-651.

20. van Der Linden W, Ericson R. Colles fracture: how should its displacement be measured and how should it be immobilized? J Bone Joint Surg Am. 1981;63(8):1285-1288.

21. Villar RN, Marsh D, Rushton N, Greatorex RA. Three years after Colles' fracture. J Bone Joint Surg Br. 1987;69(4):635-638.

22. Grewal R, MacDermid JC. The risk of adverse outcomes in extraarticular distal radius fractures is increased with malalignment in patients of all ages but mitigated in older patients. J Hand Surg Am. 2007;32(7):962-970.

23. Anzarut A, Johnson JA, Rowe BH, Lambert RG, Blitz S, Majumdar SR. Radiologic and patient-reported functional outcomes in an elderly cohort with conservatively treated distal radius fractures. J Hand Surg Am. 2004;29(6):1121-1127.

24. Azzopardi T, Ehrendorfer S, Coulton T, Abela M. Unstable extraarticular fractures of the distal radius: a prospective, randomised study of immobilisation in a cast versus supplementary percutaneous pinning. J Bone Joint Surg Br. 2005;87(6):837-840.

25. Roumen RM, Hesp WL, Bruggink ED. Unstable Colles' fractures in elderly patients. A randomised trial of external fixation for redisplacement. J Bone Joint Surg Br. 1991;73:307-311.

26. Synn AJ, Makhni EC, Makhni MC, Rozental TD, Day CS. Distal radius fractures in older patients: is anatomic reduction necessary? Clin Orthop Relat Res. 2009;467(6):1612-1620.

27. Hegeman JH, Oskam J, Vierhout PA, Ten Duis HJ. External fixation for unstable intra-articular distal radial fractures in women older than 55 years. Acceptable functional end results in the majority of the patients despite significant secondary displacement. Injury. 2005;36(2):339-344.

28. Young BT, Rayan GM. Outcome following nonoperative treatment of displaced distal radius fractures in low-demand patients older than 60 years. J Hand Surg Am. 2000;25(1):19-28.

29. Kelly AJ, Warwick D, Crichlow TP, Bannister GC. Is manipulation of moderately displaced Colles' fracture worthwhile? A prospective randomized trial. Injury. 1997;28(4):283-287.

30. Board T, Kocialkowski A, Andrew G. Does Kapandji wiring help in older patients? A retrospective comparative review of displaced intra-articular distal radial fractures in patients over 55 years. Injury. 1999;30(10):663-669.

31. Fujii K, Henmi T, Kanematsu Y, Mishiro T, Sakai T, Terai T. Fractures of the distal end of radius in elderly patients: a comparative study of anatomical and functional results. J Orthop Surg (Hong Kong). 2002;10(1):9-15.

32. McQueen MM, Court-Brown CM. Increasing age and fractures of the distal radius. Curr Orthop. 2003;17:360-368.

33. Handoll HH, Madhok R. Conservative interventions for treating distal radial fractures in adults. Cochrane Database Syst Rev. 2003;2: CD000314. 
34. Dias JJ, Wray CC, Jones JM, Gregg PJ. The value of early mobilisation in the treatment of Colles' fractures. J Bone Joint Surg Br. 1987;69(3):463-467.

35. Chung KC, Shauver MJ, Birkmeyer JD. Trends in the United States in the treatment of distal radial fractures in the elderly. J Bone Joint Surg Am. 2009;91(8):1868-1873.

36. Chung KC, Squitieri L, Kim HM. Comparative outcomes study using the volar locking plating system for distal radius fractures in both young adults and adults older than 60 years. J Hand Surg Am. 2008;33(6):809-819.

37. Orbay JL, Fernandez DL. Volar fixed-angle plate fixation for unstable distal radius fractures in the elderly patient. J Hand Surg Am. 2004;29(1):96-102.

38. Jupiter JB, Ring D, Weitzel PP. Surgical treatment of redisplaced fractures of the distal radius in patients older than 60 years. $J$ Hand Surg Am. 2002;27(4):714-723.

39. Beharrie AW, Beredjiklian PK, Bozentka DJ. Functional outcomes after open reduction and internal fixation for treatment of displaced distal radius fractures in patients over 60 years of age. J Orthop Trauma. 2004;18(10):680-686.

40. Arora R, Gabl M, Gschwentner M, Deml C, Krappinger D, Lutz M. A comparative study of clinical and radiologic outcomes of unstable Colles type distal radius fractures in patients older than 70 years: nonoperative treatment versus volar locking plating. J Orthop Trauma. 2009;23(4):237-242.

41. Anderson R, O'Neil G. Comminuted fractures of the distal end of the radius. Surg Gynecol Obstet. 1944;78:434-440.

42. Atroshi I, Brogren E, Larsson GU, Kloow J, Hofer M, Berggren AM. Wrist-bridging versus non-bridging external fixation for displaced distal radius fractures: a randomized assessor-blind clinical trial of 38 patients followed for 1 year. Acta Orthop. 2006;77(3):445-453.

43. Aktekin CN, Altay M, Gursoy K, Aktekin LA, Ozturk AM, Tabak AY. Comparison between external fixation and cast treatment in the management of distal radius fractures in patients aged 65 years and older. J Hand Surg Am. 2010;35(5):736-742.

44. Wolfe SW, Austin G, Lorenze M, Swigart CR, Panjabi MM. A biomechanical comparison of different wrist external fixators with and without K-wire augmentation. J Hand Surg Am. 1999;24(3):516-524.

45. Fu YC, Chien SH, Huang PJ, et al. Use of an external fixation combined with the buttress-maintain pinning method in treating comminuted distal radius fractures in osteoporotic patients. J Trauma. 2006;60(2):330-333.

46. Szabo RM, Weber SC. Comminuted intraarticular fractures of the distal radius. Clin Orthop Relat Res. 1988;(230):39-48.

47. Mah ET, Atkinson RN. Percutaenous Kirschner wire stabilization following closed reduction of Colles' fractures. J Hand Surg Br. 1992;17(1):55-62.

48. Clancey GJ. Percutaneous Kirschner wire fixation of Colles' fractures. A prospective study of thirty cases. J Bone Joint Surg Am. 1984;66(7):1008-1014.
49. Lenoble E, Dumontier C, Goutallier D, Apoil A. Fracture of the distal radius. A prospective comparison between trans-styloid and Kapandji fixations. J Bone Joint Surg Br. 1995;77(4):562-567.

50. Handoll HH, Watts AC. Bone grafts and bone substitutes for treating distal radial fractures in adults. Cochrane Database Syst Rev. 2008;2:CD006836.

51. Sanchez-Sotelo J, Munuera L, Madero R. Treatment of fractures of the distal radius with a remodellable bone cement: a prospective, randomised study using Norian SRS. J Bone Joint Surg Br. 2000;82(6):856-863.

52. Larsson S, Bauer TW. Use of injectable calcium phosphate cement for fracture fixation: a review. Clin Orthop Relat Res. 2002;(395):23-32.

53. Huber FX, Hillmeier J, Herzog L, McArthur N, Kock HJ, Meeder PJ. Open reduction and palmar plate-osteosynthesis in combination with a nanocrystalline hydroxyapatite spacer in the treatment of comminuted fractures of the distal radius. J Hand Surg Br. 2006;31(3): 298-303.

54. Going S, Lohman T, Houtkooper L, et al. Effects of exercise on bone mineral density in calcium-replete postmenopausal women with and without hormone replacement therapy. Osteoporos Int. 2003;14(8):637-643.

55. Fiatarone MA, Marks EC, Ryan ND, Meredith CN, Lipsitz LA, Evans WJ. High-intensity strength training in nonagenarians: effects on skeletal muscle. JAMA. 1990;263(22):3029-3034.

56. Dawson-Hughes B, Dallal GE, Krall EA, Sadowski L, Sahyoun N, Tannenbaum S. A controlled trial of the effect of calcium supplementation on bone density in postmenopausal women. $N$ Engl J Med. 1990;323(13):878-883.

57. Dawson-Hughes B, Harris SS, Krall EA, Dallal GE. Effect of calcium and vitamin D supplementation on bone density in men and women 65 years of age or older. $N$ Engl J Med. 1997;337(10):670-676.

58. Black DM, Cummings SR, Karpf DB, et al. Randomised trial of effect of alendronate on risk of fracture in women with existing vertebral fractures. Fracture Intervention Trial Research Group. Lancet. 1996;348(9041):1535-1541.

59. Cummings SR, Black DM, Thompson DE, et al. Effect of alendronate on risk of fracture in women with low bone density but without vertebral fractures: results from the Fracture Intervention Trial. JAMA. 1998;280(24):2077-2082.

60. Neer RM, Arnaud CD, Zanchetta JR, et al. Effect of parathyroid hormone (1-34) on fractures and bone mineral density in postmenopausal women with osteoporosis. N Engl J Med. 2001;344(19):1434-1441.

61. Ettinger B, Black DM, Mitlak BH, et al. Reduction of vertebral fracture risk in postmenopausal women with osteoporosis treated with raloxifene: results from a 3-year randomized clinical trial. Multiple Outcomes of Raloxifene Evaluation (MORE) Investigators. JAMA. 1999;282(7):637-645.

62. Chesnut CH III, Silverman S, Andriano K, et al. A randomized trial of nasal spray salmon calcitonin in postmenopausal women with established osteoporosis: the prevent recurrence of osteoporotic fractures study. PROOF Study Group. Am J Med. 2000;109(4):267-276.
Clinical Interventions in Aging

\section{Publish your work in this journal}

Clinical Interventions in Aging is an international, peer-reviewed journal focusing on evidence-based reports on the value or lack thereof of treatments intended to prevent or delay the onset of maladaptive correlates of aging in human beings. This journal is indexed on PubMed Central, MedLine, the American Chemical Society's 'Chemical Abstracts Ser-

\section{Dovepress}

vice' (CAS), Scopus and the Elsevier Bibliographic databases. The manuscript management system is completely online and includes a very quick and fair peer-review system, which is all easy to use. Visit http://www.dovepress.com/testimonials.php to read real quotes from published authors. 